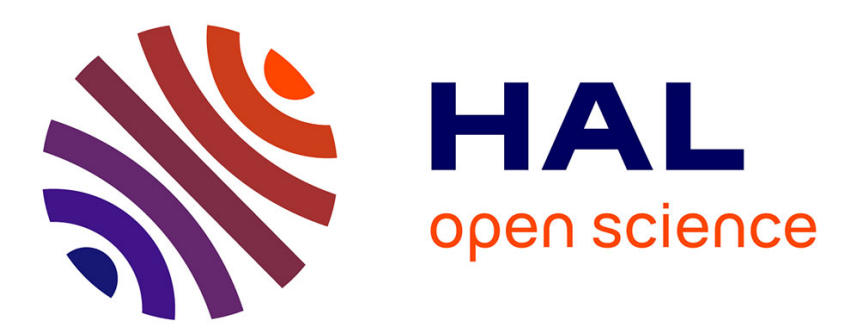

\title{
Lombard Effect, Ambient Noise and Willingness to Spend Time and Money in a Restaurant Amongst Older Adults
}

Pasquale Bottalico, Rachael Piper, Brianna Legner

\section{- To cite this version:}

Pasquale Bottalico, Rachael Piper, Brianna Legner. Lombard Effect, Ambient Noise and Willingness to Spend Time and Money in a Restaurant Amongst Older Adults. Forum Acusticum, Dec 2020, Lyon, France. pp.3055-3062, 10.48465/fa.2020.0860 . hal-03235298

\section{HAL Id: hal-03235298 \\ https://hal.science/hal-03235298}

Submitted on 26 May 2021

HAL is a multi-disciplinary open access archive for the deposit and dissemination of scientific research documents, whether they are published or not. The documents may come from teaching and research institutions in France or abroad, or from public or private research centers.
L'archive ouverte pluridisciplinaire HAL, est destinée au dépôt et à la diffusion de documents scientifiques de niveau recherche, publiés ou non, émanant des établissements d'enseignement et de recherche français ou étrangers, des laboratoires publics ou privés. 


\title{
LOMBARD EFFECT, AMBIENT NOISE AND WILLINGNESS TO SPEND TIME AND MONEY IN A RESTAURANT AMONG OLDER ADULTS
}

\author{
Pasquale Bottalico $^{1} \quad$ Rachael N. Piper ${ }^{1} \quad$ Brianna Legner $^{1}$ \\ ${ }^{1}$ Department of Speech and Hearing Science, University of Illinois, Urbana-Champaign, Illinois, USA \\ pb81@illinois.edu
}

\begin{abstract}
Dining establishments are often characterized by high levels of background noise, which represents a barrier for an effective communication. This particularly affects people suffering from hearing problems. Moreover, noise levels exceeding normal conversational levels causes a subconscious phenomenon called the Lombard Effect, an involuntary tendency to increase the amount of vocal effort when talking in the presence of noise. The primary aim of the current study was to understand the effect of noise on vocal effort and speech intelligibility in a restaurant setting for adults over 60 years old with and without hearing loss. The secondary aim was to evaluate how their perception of disturbance in the communication, their willingness to spend time and money in a restaurant was affected by the varying levels of background noise. The results of this study showed background noise levels, lower than $50 \mathrm{~dB}(\mathrm{~A})$, will allow the senior customers to minimize their vocal effort and to allow for more understanding than $50 \%$ of the conversation, even for those impacted by moderate to severe hearing loss. This limit will also keep the disturbance of the communication below $50 \%$ and the willingness to spend time and money in a restaurant over $50 \%$.
\end{abstract}

\section{INTRODUCTION}

Prior to Coronavirus (COVID-19), for many, going out for a meal had become the new standard to spend time with family, friends, and conducting business [1]. Before the 1990's, "excessive" restaurant noise was considered insignificant to diners and critics, which added to the atmosphere of the eating establishment [2]. A restaurant's atmosphere is vital to keeping and enticing new patrons; by creating a connection between taste and sound, music selections can subconsciously cause the diners to increase their overall food and beverage consumption and bill at a restaurant [2-3].Depending on the age group you ask, several individuals might recall the noisy environment more than the food [4]. This is especially problematic for everyone as dynamic background noise, such as restaurants [1], degrades the understanding of conversations. The relationship between noise and conversations contributes to an individual's overall "quality of life" (QOL). Quality of life has been defined to be the self-perception of life satisfaction, fulfillment, and happiness [5]. A key term when discussing quality of life are "positive indicators," which translates into an object, person, or environment that is providing improvement to the individuals life [6]. QOL is important to the overall topic of the current study, as individuals place value on the luxury of dining out.

In recent years, there has been increased awareness towards the acoustics of eating establishments with the goal of improving speech intelligibility [7-8]. Restaurants are designed to look aesthetically pleasing and modernized, which often is portrayed with a lack of materials used to absorb sound. The lack of these materials tends to increase the overall noise level in the restaurant which has caused diners, critics, and audiologists to take notice [2, 4, 7-10]. In a survey by Zagat [11], individuals voted noise to be the second complaint of restaurants, followed by service [8]. However, when the survey was repeated, it revealed noise was now the first complaint of patrons [12]. With noise levels growing, restaurant critics have begun to carry sound level meters to evaluate the noise levels during their busiest times [2].

Restaurants have a wide range of noise during hours of operation. Typical restaurant noise can fluctuate throughout the course of an evening ranging from 65 $\mathrm{dB}(\mathrm{A})$ up to as high as $91 \mathrm{~dB}(\mathrm{~A})$, which causes increased difficulty to be heard and understood by anyone in these extreme dining settings $[1,2,4,8,10,13]$. While many restaurants noise levels have been recorded up to 85 $\mathrm{dB}(\mathrm{A})$ in recent years, there are several other dining facilities that may exceed this measurement and have not been recorded. These problematic levels affects not only the older adults, but also the whole of the restaurant industry who eagerly looks to entice new patrons with flattering atmospheres and delicious meals, all while using acoustical impermeable decor.

Noise can also be the result of maximum capacities in restaurants. In Neilson et al.'s study [10], the authors discovered noise annoyance correlated with patron density. The study defined patron density as the "patrons

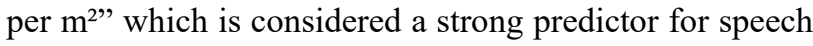
difficulty, arguing dining establishments should no longer be thought to have "maximum capacity" but rather "acoustical capacity," allowing for dining enjoyment within reasonable noise levels $[7,10]$. Other researchers argued for reduced reverberation, also known as "universal design" [7], by making atmospheric adjustments like carpeting, sound absorbent panels, or curtains on the walls and ceilings [2, 7, 9]. While remodeling can be expensive up front, some restaurant owners have found even more success in their business 
after acoustics refurbishment. The presence of high levels of noise in an environment devoted to communication, such as restaurants, leads to two effects: the Lombard Effect and the Cocktail Party Effect.

In 1909, Etienne Lombard made the astounding discovery of the changes in voice in the presence of background noise [14]. During patient testing, Lombard observed the patient would raise their voice in the presence of background noise, then return to normal levels when the noise dissipated [15]. This involuntary action of the speaker increasing their vocal effort, while speaking in loud noise, enhancing the audibility of their voice, and later returning to their normal speaking level post-noise is named after the researcher as "the Lombard Effect." Lazarus stated the speech level corresponds with the noise level, creating a slope of 0.3-0.6 dB per noise level rise of $1 \mathrm{~dB}$ for all disturbing noise exceeding 40-50 $\mathrm{dB}(\mathrm{A})$ (1986). However, a noise level of 30-40 dB(A) shows minimal effect on an individual's speech level [16].

In 1953, Cherry [17] presented the findings of the differences in recognition and discrimination of speech. The initial experiment examined an individual's ability to perceive another speaker's words while others are conversing at the same time - or known as the "cocktail party problem" [17-18] or the "Cocktail Party Effect" (CPE). The brain's ability to selectively attend to different speech streams has been assessed by several researchers since then to ascertain how we are able to understand someone in noise. To paraphrase listening in complex environments (such as restaurants) causes an increase in overall brain activity, more specifically the auditory cortex and thalamus. Researchers attribute these cortical areas as due to the individual attempting to attend to auditory cues and ignore the background noise [19]. Golumbic et al. [20] reinforced these ideas when examining the role of attention influenced by using lowfrequency neuronal oscillations measured by subdural electrocorticography (ECoG) to attend to the signal and ignore the "Cocktail Party" simulation. The study suggested due to the brain's dynamic activity, it not only uses low-frequency phases, but also high-frequency amplitude fluctuations causing the two to combine [20]. In relation to the auditory cortexes, attention focuses on the primary speech signal modulations and enhances them over time, reducing the attention focused on residual speech occurring - or better explained as "selective attention."

Recently in 2018, Bottalico began to study the Lombard effect in a restaurant setting [21]. Bottalico identified the Lombard effect in a controlled laboratory setting, using typical restaurant noise. The noise was presented at different levels from $35 \mathrm{~dB}(\mathrm{~A})$ to $85 \mathrm{~dB}(\mathrm{~A})$ with $5 \mathrm{~dB}$ increments. After reading "The Rainbow Passage" [22], in each noise condition, participants were asked to score their perceived disturbance, how much time they would stay, and how much money they would be willing to spend. The results indicated a change-point of the Lombard effect at $57.3 \mathrm{~dB}(\mathrm{~A})$, with a slope of the lower segment being $0.31 \mathrm{~dB} / \mathrm{dB}$ and the upper segment as being $0.54 \mathrm{~dB} / \mathrm{dB}$ slope. Additionally, this group's scores for disturbance, time, and money started to decrease at
$52.5 \mathrm{~dB}(\mathrm{~A})$ (disturbance $=52.2 \mathrm{~dB}(\mathrm{~A})$, willingness $=51.3$ $\mathrm{dB}(\mathrm{A})$, money $=52.5 \mathrm{~dB}(\mathrm{~A}))$.

The population analyzed by Bottalico [21] consisted of normal hearing college students aged $18-28$. This group of people, defined as millennials, "appears to have a higher tolerance for sound" due to their usage of headphones and loud music tastes. Moreover, millennials tend to spend less money in dining out possibly because of their contribution to overall outstanding student loan debt in the United States, which is estimated to be $\$ 1.38$ trillion and still climbing [23]. This limits the results of Bottalico [21] to the specific population analyzed.

While millennials are just beginning a new stage of life, the likelihood to be agitated by environmental features is smaller; however, consideration for those who are older, "The Baby Boomers," is needed. Over several decades, humans have managed to eliminate most infectious diseases through better hygiene, antibiotics, and vaccines which subsequently has increased human life expectancy upwards of thirty years [24-25]. Shen et al. [26] quoted that in $2009,13 \%$ of the United States population was 65 years and older, which would eventually increase to $19.3 \%$ by 2030 . The National Institute on Aging (NIA) states, in their "2020-2025 Strategic Directions for Research," plan there are approximately 49 million Americans aged 65 and older, which is emphasized to be the largest number of older adults than any other time in history [27]. In recent years, there has been a push for research on understanding the process of aging to better assist these individuals not just in terms of healthcare through prevention, progression, and prognosis [27] - or "healthy aging" - but also in terms of staying connected to society [25].

The American Association of Retired Persons (AARP) memberships permits those aged 50 and older to apply for "full benefits"; therefore, an "older adult" or "senior" can be as young as fifty. It is, however, more common to see individuals who are 60 years and older already contemplating retirement or have fully retired due to the different definitions of retirement in various job fields [28-29]. This population of older adults are more likely to have increased wealth due to pensions, social security, and welfare [30]. While some older adults have chosen to retire, some or most are still actively participating in the world, especially in the dining out experience. However, comorbidities of older adults are high and includes hearing loss.

The World Health Organization estimated forty-six million individuals are distressed by some degree of hearing loss [31]. The National Institute of Deafness and Other Communication Disorders (NIDCD) reinforced hearing loss increases with age and are most commonly found in Caucasian adults aged 60-69 [32]. Goman and Lin [33] stated the most common type of hearing loss in this age group is mild sensorineural hearing loss. For older adults, independent of hearing status, restaurants are one of the primary environments noted to have increased difficulty $[1,18,34]$. As many as $52 \%$ of individuals are disturbed and $88 \%$ have problems conversing [7]. It has been proven, as we age, older adults have reduced, bilateral auditory region activity, in conjunction with increased frontal and posterior parietal lobe activity. 
These alterations create a broader processing ability causing a subconscious compensatory strategy to speechin-noise situations [35]. The broad networking can lead to increased listening effort causing fatigue [7, 18]. However, untreated hearing loss in older adults not only causes auditory deprivation and increased listening efforts, but the potential for cognitive decline and decrease overall quality of life [36].

Additionally, there is the phenomenon of older adults having correctly heard information presented, but it is misperceived (even with context); and to reduce embarrassment, older adults will not ask for repetition [37], contributing to the stress of dining out. This event is caused by the deficit of seniors' reliance on linguistical knowledge to counteract reduced processing speeds for speech-in-noise environments [37]. Since high frequency hearing loss is most common, there is some variance in responses by older adults in speech-in-noise situations [38], which could be explained by the reverberation of the restaurant setting [9]. With older adults, it is critical to be actively participating in providing them with the best signal-to-noise ratio (SNR) as possible, with or without the assistance from hearing devices, in order to create hearing- and age-friendly environments, like restaurants, to reduce the risk of isolation and depression due to the lack of the ability to socialize [39].

Heinrich et al. [40] found speech perception correlated with hearing sensitivity levels, even when hearing loss was ruled out. As part of the auditory assessment battery, it is typical for patients to receive a speech intelligibility test. The purpose of an intelligibility test not only assists in confirmation of the hearing loss, but also helps the audiologist to understand where the patient is having deficits in real-world conversations [41]. There are various reasons as to why speech intelligibility in the presence of noise is problematic. Primarily the most significant reason is the fundamental frequency of the voice per gender, which is lower for males versus females [42]. However, Bronkhorst [42] continued to note the environment, distance from the primary talker, distance from other conflicting talkers varies greatly on intelligibility. The study reinforced even with changeable qualities, the comorbidities of limited vocal output and poor pronunciation by a speaker or the possibility of hearing loss, contributed to deficits in speech intelligibility [42]. New studies to evaluate vocal reliability in older adults have become more critical; and adults over the age of 65 have been reported to have a $25 \%$ chance of developing a voice disorder [43]. With the combination of vocal fatigue, hearing loss, and maximum seating occupancy in restaurants, it is imperative to assess the level of noise older adults begin to experience less than $50 \%$ intelligibility.

Therefore, there is a glaring need to consider the senior population and their needs regarding dining out, with the aim of creating more age-friendly communities.

With the goal of understanding how the senior population will react to noise in a restaurant setting, in terms of voice production (the Lombard Effect) and speech perception (the Cocktail Party Effect), the following research will investigate five different outcomes. In this study, thirtyone participants, aged 60 and older, were asked to read a passage in the presence of eleven randomized noise conditions ranging $35 \mathrm{~dB}(\mathrm{~A})$ to $85 \mathrm{~dB}(\mathrm{~A})$. After each passage reading, an intelligibility test was performed, and a visual analog scale was handed to the participant to rate their amount of disturbance and willingness to spend time and money in a restaurant. The aim of this study will attempt to answer the following research questions:

1) What is the level of noise at which older adults experience the Lombard effect?

2) What are older adults' amount of disturbance perceived in each of the eleven noise conditions?

3) How much time they would be willing to stay in the environment?

4) How much money they would be willing to spend in the same environment?

5) What is the noise level at which older adults are no longer able to have an intelligible conversation?

\section{METHODS}

\subsection{Participants}

A total of 42 individuals were recruited for the study (females $=24$, males $=18$ ). Inclusion criteria required the participant to be over the age of sixty years and have normal hearing $(<25 \mathrm{~dB}$ HL) or hearing loss $(>25 \mathrm{~dB}$ HL); additionally, participants must be proficient English speakers, since the intelligibility test will be given in English. Exclusion criteria included those under the age of sixty, not a native English speaker, and an air-bone gap greater than $15 \mathrm{~dB} \mathrm{HL}$ without a previous medical consultation with an otolaryngologist (ENT). The participants signed a consent form, completed a demographics form, and underwent a hearing test prior to completion of the experiment. The hearing test included otoscopy, tympanometry, speech reception thresholds, and air and bone conduction audiometry. This resulted in thirty-one participants; the final participant demographics are recorded in Table I.

\begin{tabular}{|c|c|c|c|}
\hline Demographic & $\begin{array}{c}\text { Normal } \\
\text { Hearing }\end{array}$ & $\begin{array}{c}\text { Mild } \\
\text { HL }\end{array}$ & $\begin{array}{c}\text { Moderate - } \\
\text { Severe HL }\end{array}$ \\
\hline Male & 2 & 4 & 8 \\
\hline Female & 8 & 6 & 3 \\
\hline Caucasian & 10 & 10 & 11 \\
\hline English speaker & 10 & 10 & 11 \\
\hline Smoker & 0 & 0 & 0 \\
\hline Acid Reflux & 5 & 2 & 2 \\
\hline Asthma & 2 & 0 & 0 \\
\hline Allergies & 4 & 5 & 7 \\
\hline Lung-Heart Disease & 3 & 0 & 3 \\
\hline Speech Therapy & 0 & 0 & 1 \\
\hline Voice Training & 2 & 1 & 2 \\
\hline
\end{tabular}

Table 1. The demographics of the final 31 participants separated by hearing loss category.

\subsection{Procedure}

After participants confirmed their age, they were scheduled to participate in the study. Prior to completing the hearing test, participants reviewed their hearing 
history with the graduate student. Afterwards, otoscopy and tympanometry at $226 \mathrm{~Hz}$ were performed to rule out a conductive pathology (primarily cerumen or middle ear fluid).

After completion of the hearing test, the individual continued with the Lombard Effect testing, speech-innoise intelligibility testing, and scored on a visual analogue scale their perceptual responses of (1) communication disturbance, (2) willingness to spend time, and (3) willingness to spend money in a restaurant. Participants completed all components of the study in one or two forty-five to sixty-minute sessions, resulting from scheduling conflicts and/or participant fatigue.

\subsection{Hearing loss categorization}

After the hearing evaluation, participants were grouped in three categories. These categories were determined by the collective pure-tone averages of $2000 \mathrm{~Hz}, 4000 \mathrm{~Hz}$, and $8000 \mathrm{~Hz}$ of both ears per participant. The calculated high frequency average was classified into: 1) normal hearing [ $<25 \mathrm{~dB}$ HL], 2) mild sensorineural hearing loss [26-40 $\mathrm{dB} \mathrm{HL}], 3)$ moderate, severe, \& profound sensorineural hearing loss [41+ dB HL]. All categorization was based on ASHA [44] and Clark [45] degrees of hearing loss.

\subsection{Measuring the Lombard Effect}

Participants were fit with the head-mounted microphone connected to a portable recorder. Then, participants were asked to read in the presence artificial restaurant noise the first six sentences of "The Rainbow Passage" [22], which is used by Speech Language Pathologists to assess and monitor voice and articulation disorders. The synthesized noise was presented in a random order at eleven levels from $35 \mathrm{~dB}(\mathrm{~A})$ to $85 \mathrm{~dB}(\mathrm{~A})$ with $5 \mathrm{~dB}$ interval. The speech was recorded with the software Audacity 2.0.6 (SourceForge, La Jolla, CA). Participants were instructed, by the undergraduate student assistant, with the following: "Each time, I [the listener] would like you to pretend that we are talking in a restaurant and you are telling the story to me. Make sure that I understand you equally well each time."

\subsection{Measuring Speech Intelligibility in Noise}

The participants completed a speech-in-noise intelligibility test for each of the eleven, randomized noise conditions. Our intelligibility test was designed using the 250-300 standardized Northwestern University \#6 [46] words available to all audiologists. These words were recorded using the voice of an undergraduate student assistant; the words were individually clipped and then randomized into eleven, twenty-word lists. These recordings were then played through a Head and Torso Simulator (HATS)(GRAS, Holte, Denmark), placed at one meter distance from the participant, to eliminate participants' reliance on visual cues to lip-read. The word lists were presented at a level of $66 \mathrm{~dB}(\mathrm{~A})$, corresponding to a raised vocal effort at one meter of distance [47].
Participants were asked to repeat the word pronounced by the HATS. Intelligibility scores were measured as percentage of words correct.

\subsection{Recording Disturbance, Time, \& Budget Scores}

Self-reported communication disturbance and willingness to spend time and money were measured on visual analog scales on paper. The participant was instructed to place a vertical tick on the horizontal line regarding their amount of disturbance, time, and money per noise condition. The paper document was then scanned and uploaded to be measured, in centimeters, using Adobe Acrobat Pro DC Software and the Adobe Software Measurement Tool. The responses were then recorded in an Excel spreadsheet according to the participant's identification number.

\subsection{Analysis of Voice Recordings}

The audio recordings of participants were pulled from an SD card and segmented using ELAN software (v5.8). Each of the eleven "Rainbow Passage" segments were saved according to the participants identification number and noise level condition. MATLAB (R2017a) was used for speech signal analysis. In each condition, the equivalent SPL was measured. For each condition, the mean value of the SPL was obtained per subject. For each subject, the average of SPL among the conditions was computed and subtracted from each mean SPL values for that subject (termed $\triangle \mathrm{SPL}$ ). This within-subject centering was performed in order to evaluate the variation in the subject's vocal behavior in the different noise conditions from their typical vocal behavior (mean value of the SPL per subject). Each participant was identified by their identification number, gender, age and type of hearing loss.

\subsection{Equipment \& Room Measurements}

The study was performed in an sound-attenuated booth. Reverberation time was measured in the sound booth from the impulse responses (IRs) generated by balloon pops [47]. The four IRs were recorded in two source positions and two microphone positions by means of an NTI Measurements microphone M2211 (Class 1 frequency response) and analyzed in one-third octave bands by means of an NTI XL2 Audio and Acoustic Analyzer. The reverberation time (T20) at midfrequencies in the room was $0.05 \mathrm{~s}$, while the background noise was $22.5 \mathrm{~dB}(\mathrm{~A})$. The hearing test will be performed using a calibrated tympanometer (TympStar, GrasonStadler, Eden Prarie, MN), audiometer (GSI 61, GrasonStadler, Eden Prarie, MN), insert phones (3M E-A-

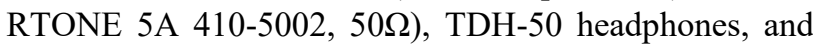
bone oscillator. The participants' speech will be recorded using a head-mounted microphone (Beta 54 WBH54, Shure, Niles, IL) and connected to an audio interface (US-, TASCAM [DR44], Montebello, CA). Synthetic restaurant noise was emitted by two directional speakers 
(High performance $100 \mathrm{~dB}$ speaker, E3 Diagnostics, Arlington Heights, IL) placed at $45^{\circ}$ to the sides of the participants using the same stimuli.

\section{RESULTS}

The $\triangle$ SPL was measured at each of the 11 noise levels between 35 and $85 \mathrm{~dB}(\mathrm{~A})$, as shown in Figure 1. A piecewise linear model was fit to the response variable, $\triangle \mathrm{SPL}$, and the predictor, Ln. The presence of Hearing Loss (HL) did not statistically influence the Lombard Effect. The piecewise linear model individuates a breakpoint in $\mathrm{Ln}$ at $58.3 \mathrm{~dB}(\mathrm{~A})$ (CI 95\% lower: 53.4, CI $\%$ upper: 63.3). The slope of the lower segment was 0.27 , and the upper was 0.51 , with an R-squared of 0.86 .

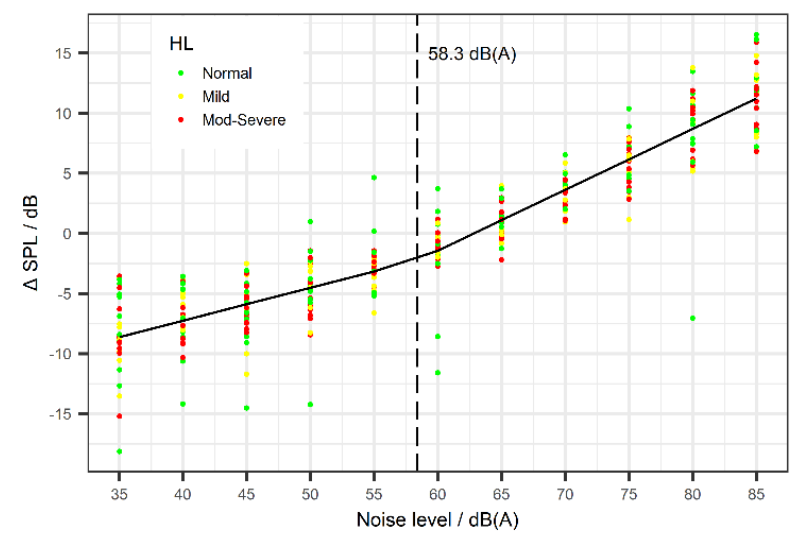

Figure 1. $\triangle$ SLP per each of the 11 noise conditions.

Self-reported communication disturbance was measured at each of the 11 noise levels (Figure 2). A piecewise linear model was fit to the response variable, disturbance (\% of "very high") and the predictors, Ln and HL. The piecewise linear model individuates two breakpoints, the first at $51.6 \mathrm{~dB}(\mathrm{~A})(\mathrm{CI} 95 \%$ lower: 41.4 , CI \% upper: 60.3) and the second at $66.9 \mathrm{~dB}(\mathrm{~A})$ (CI 95\% lower: 62.0, CI \% upper: 71.2). The slope of the lower segment was 1.77 percent-points per $\mathrm{dB}(\mathrm{pp} / \mathrm{dB})$, the medium was $2.78(\mathrm{pp} / \mathrm{dBA})$ and the upper was $0.83(\mathrm{pp} / \mathrm{dBA})$. In in the same noise level condition, compared to participants with normal hearing, participants with mild HL scored the disturbance $9.37 \%$ higher, while participants with moderate to severe HL scored the disturbance $5.87 \%$ higher. The R-squared of the model was 0.78 .

The willingness to spend time in the restaurant was measured at each of the 11 noise levels, as shown in Figure 3. A piecewise linear model was fit to the response variable, time willing to stay (\% of "A long time") and the predictors, Ln and HL. The piecewise linear model individuates a breakpoint in $\mathrm{Ln}$ at $65.8 \mathrm{~dB}(\mathrm{~A})$ (CI 95\% lower: 58.9, CI \% upper: 72.7). The slope of the lower segment was -2.27 (pp/dBA), and the upper was -1.00 (pp/dBA). In in the same noise level condition, compared to participants with normal hearing, participants with mild HL scored the time willing to stay $6.62 \%$ lower, while participants with moderate to severe HL scored the disturbance $4.79 \%$ lower. The R-squared of the model was 0.73 .

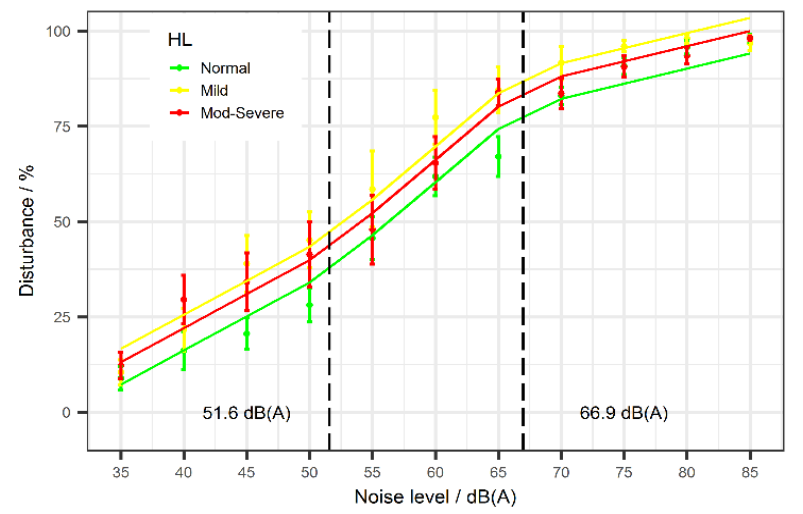

Figure 2. Amount of disturbance perceived in each noise condition.

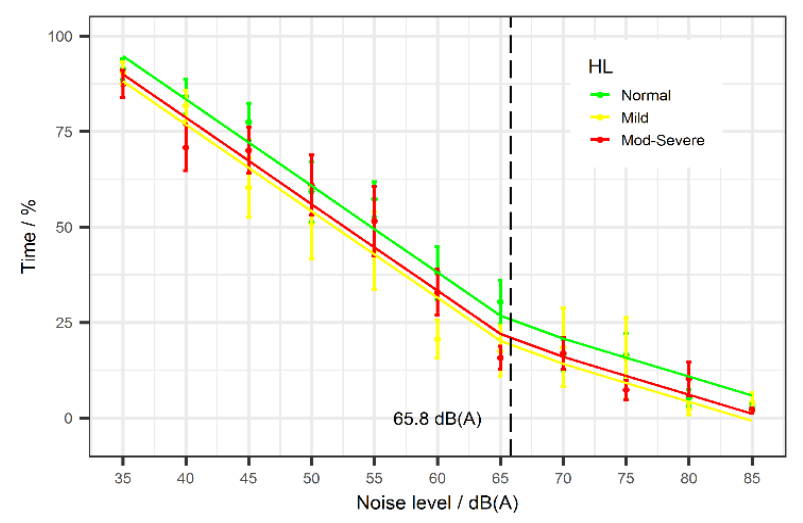

Figure 3. Amount of time willing to spend in each noise condition.

The willingness to spend money in the restaurant was measured at each of the 11 noise levels, as shown in Figure 4. A piecewise linear model was fit to the response variable, money willing to spend (\% of "All the budget") and the predictors, Ln and HL. The piecewise linear model individuates two breakpoints, the first at $54.6 \mathrm{~dB}(\mathrm{~A})$ (CI 95\% lower: 40.9, CI \% upper: 60.0) and the second at $61.99 \mathrm{~dB}(\mathrm{~A})(\mathrm{CI} 95 \%$ lower: 57.98 , CI \% upper: 65.99$)$. The slope of the lower segment was -1.80 percent-points per $\mathrm{dB}(\mathrm{pp} / \mathrm{dB})$, the medium was -3.86 $(\mathrm{pp} / \mathrm{dBA})$ and the upper was $-0.87(\mathrm{pp} / \mathrm{dBA})$. In in the same noise level condition, compared to participants with normal hearing, participants with mild HL scored the time willing to stay $12.06 \%$ lower, while participants with moderate to severe HL scored the disturbance $8.11 \%$ lower.

The intelligibility in the restaurant was measured at each of the 11 noise levels, as shown in Figure 5. A piecewise linear model was fit to the response variable, intelligibility scores ( $\%$ of correct word recognized) and as predictors, Ln, HL and their interaction. The piecewise linear model individuates two breakpoints, the first at $51.2 \mathrm{~dB}(\mathrm{~A})$ (CI 95\% lower: 48.2, CI \% upper: 54.2) and 
the second at $71.3 \mathrm{~dB}(\mathrm{~A})(\mathrm{CI} 95 \%$ lower: 68.4, CI \% upper: 74.2). Because of the interaction between $\mathrm{Ln}$ and $\mathrm{HL}$, in each of the three segment there is a slope for each HL levels (Normal, Mild and Moderate-Severe). The slopes of the lower segments were $-1.08,-0.98$, and -0.32 percent-points per $\mathrm{dB}(\mathrm{pp} / \mathrm{dB})$ for participants with Normal Hearing, Mild HL and Moderate-Severe HL, respectively. The slopes of the medium segments for the three groups were $-3.39,-3.30$, and -2.64 percent-points per $\mathrm{dB}(\mathrm{pp} / \mathrm{dB})$, while the slopes of the upper segments for the three groups were $-0.65,-0.56$, and 0.10 percentpoints per $\mathrm{dB}(\mathrm{pp} / \mathrm{dB})$. The R-squared of the model was 0.85 .

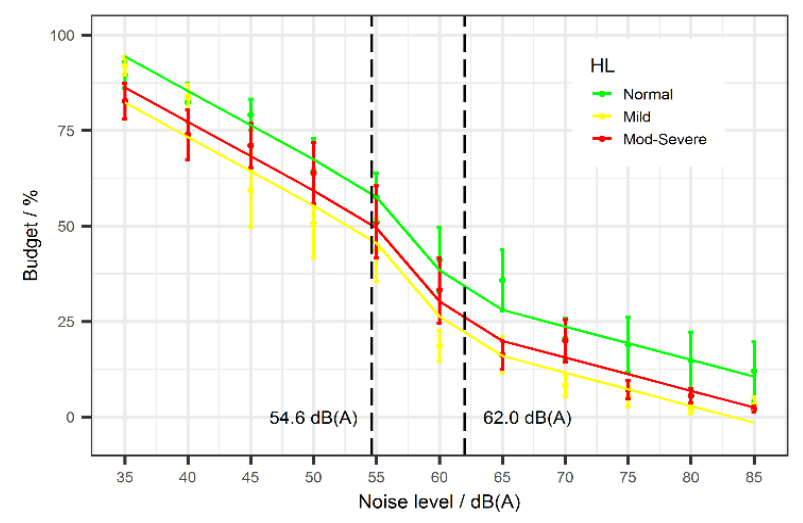

Figure 4. Amount of budget willing to spend in each noise condition.

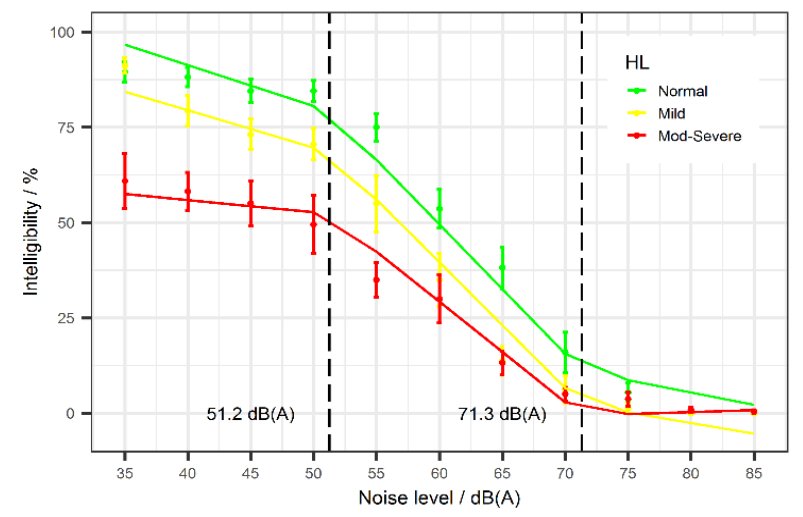

Figure 5. Intelligibility percentages by noise condition.

\section{CONCLUSION}

The goal of this study was to identify the starting point of Lombard Effect in older adults which occurred at 58.3 $\mathrm{dB}(\mathrm{A})$, as well as the slope of the Lombard Effect which was identified at the lower segment as 0.27 and the upper segment as 0.51 . As the noise increased, so did older adults' amount of perceived disturbance, beginning at $51.6 \mathrm{~dB}(\mathrm{~A})$ and a second beginning saturation levels at $66.9 \mathrm{~dB}(\mathrm{~A})$, as well as decreased willingness to spend time, starting saturation levels at $65.8 \mathrm{~dB}(\mathrm{~A})$, and money, starting at $54.6 \mathrm{~dB}(\mathrm{~A})$ and reaching saturation by 62.0 $\mathrm{dB}(\mathrm{A})$ in the synthesized restaurant setting. Additionally, at one meter's distance with one talker, intelligibility results reflected that moderate-to-severe hearing loss participants already were at approximately 50\% correct word understanding in the lowest noise level condition even when they were unaided. By $70 \mathrm{~dB}(\mathrm{~A})$ all hearing categories (normal, mild, and moderate-to-severe) were almost or at $0 \%$ correct words. This is a problem as many restaurants can exceed this threshold by $15 \mathrm{~dB}$ or more in real-world environments causing many patrons to be unable to have an effective communication when they go out to dine. The results showed that a background noise level lower than $50 \mathrm{~dB}(\mathrm{~A})$ will allow the senior customers to minimize their vocal effort and to understand more than $50 \%$ of the conversation even for people with moderate to severe hearing loss. The same limit will also keep the disturbance of the communication below the $50 \%$ and the willingness to spend time a money in a restaurant above the $50 \%$.

\section{REFERENCES}

[1] C. Lebo, M. F. W. Smith, E.R. Mosher, S. J. Jelonek, D. R. Schwind, K. E. Decker, H. J. Krusemark, and P. L. Kurz: "Restaurant noise, hearing loss, and hearing aids," Western Journal of Medicine, 161, 1, pp. 45-49, 1994.

[2] J. T. Lang: "Sound and the city: Noise in restaurant critics' reviews," Food, Culture and Society, 17, 4, pp. 351-589, 2015.

[3] B. Wansink and K. Ittersum: "Fast food restaurant lighting and music can reduce calorie intake and increase satisfaction," Psychological Reports, 111, 1, pp. 228-232, 2012.

[4] L. Hannah: "Sound and the Restaurant Environment," New Zealand Acoustics, 17, 214, pp. 27-36, 2004.

[5] M. Usyal, M. J. Sirgy, E. Woo, and H. L. Kim: "Quality of life (QOL) and well-being research in tourism," Tourism Management, 53, pp. 244-261, 2016.

[6] M. J. Sirgy, A. C. Michalos, A. L. Ferriss, R. A. Easterlin, D. Patrick, and W. Pavot: "The qualityityof-life (QOL) research movement: Past, present, and future," Social indicators research, 76, 3, pp. 343466, 2006.

[7] J. H. Rindel: "Acoustical capacity as a means of noise control in eating establishments," Joint BalticNordic Acoustics Meeting, pp. 1-8, 2012.

[8] C. Spence: "Noise and its impact on the perception of food and drink," Flavour, 3, 1, pp. 1-17, 2014.

[9] M. Haywood: "Creating restaurant vibrancy without noise," Acoustics Australia, 38, 3, pp. 158- 159, 2010 . 
[10] N. O. Nielsen, M. Marschall, S. Santurette, and C. H. Jeong: "Subjective evaluation of restaurant acoustics in a virtual sound environment," Proc. of the INTER-NOISE 2016 45th International Congress and Exposition on Noise Control Engineering: Towards a Quieter Future, pp. 6140-6149, 2016.

[11] Zagat, "The state of American dining in 2016," 2016. [Online]. Available: https://www.zagat.com/b/the-state-of-americandining-in-2016. [Accessed Oct. 30, 2020].

[12] Zagat, “2018 Dining Trends Survey," 2018. [Online]. Available: https://zagat.googleblog.com/2018/01/zagatreleases-2018-dining-trends-survey. [Accessed Oct. $30,2020]$.

[13] W. M. To and A. W. L. Chung: "Restaurant noise: Levels and temporal characteristics," Noise and Vibration Worldwide, 46, 8, pp. 11-17, 2015.

[14] J. Kang: "Numerical modelling of the speech intelligibility in dining spaces," Applied Acoustics, 63, pp. 1315-1333, 2002.

[15] M. Hodgson, Z. Razavi, and G. Steininger: "Evaluation of Acoustical Environments in Eating Establishments," Building Acoustics, 16, 2, pp. 125148, 2009.

[16] J. F. Culling, R. Gocheva, Y. Li, and N. Kamaludin: "The effects of ceiling height and absorber placement on speech intelligibility in simulated restaurants," Acoustics Science \&Technology, 41, 1, pp. 223-228, 2020.

[17] E. Lombard: "Le signe de l'elevation de la voix," Annales des Maladies de l'Oreille et du Larynx, 37, pp. 101-119, 1911.

[18] H. Lane and B. Tranel: "The Lombard Sign and the Role of Hearing in Speech," Journal of Speech and Hearing Research, 14, 4, pp. 677-709, 1971.

[19] H. Brumm and S. A. Zollinger: "The evolution of the Lombard effect: 100 years of psychoacoustic research," Behaviour, 148, 11, pp. 1173-1198, 2017.

[20] P. Bottalico, I. I. Passione, S. Graetzer, and E. Hunter: "Evaluation of the Starting Point of the Lombard Effect," Acta Acustica United with Acustica, 103, 1, pp. 169-172, 2017.

[21] E. C. Cherry: "Some Experiments on the Recognition of Speech, with One and with Two Ears," Journal of the Acoustical Society of America, 25, 5, pp. 975-979, 1953.

[22] B. Gygi and V. Shafiro: "Auditory and cognitive effects of aging on perception of environmental sounds in natural auditory scenes," Journal of Speech, Language, and Hearing Research, 56, 5, pp. 1373-1388, 2013.
[23] P. C. M. Wong, A. K. Uppunda, T. B. Parrish, and S. Dhar: "Cortical mechanisms of speech perception in noise," Journal of Speech, Language, and Hearing Research, 51, 4, pp. 1026-1041, 2008.

[24] E. M. Z. Golumbic, N. Ding, S. Bickle, P. Lakatos, C. A. Schevon, G. M. McKhann, R. R. Goodman, R. Emerson, A. D. Mehta, J. Z. Simon, D. Poeppel, and C. E. Schroeder: "Mechanisms Underlying Selective Neuronal Tracking of Attended Speech at a “Cocktail Party”," Neuron, 77, 5, pp. 980-991, 2013.

[25] P. Bottalico: "Lombard effect, ambient noise, and willingness to spend time and money in a restaurant," The Journal of the Acoustical Society of America, 144, 3, pp. EL209-EL214, 2018.

[26] G. Fairbanks: Voice and articulation drillbook, 2nd edition, Harper \& Row, New York, pp. 124-139, 1960.

[27] G. E. Daniels and A. Smythe: "Student Debt and Labor Market Outcomes," AEA Papers and Proceedings, 109, pp. 171-1175, 2019.

[28] M. Tosato, V. Zamboni, A. Ferrini and M. Cesari: "The aging process and potential interventions to extend life expectency," Clinical Interventions in Aging, 2, 3, pp. 401-412, 2007.

[29] M. Larkin: "Dr. Linda Fried illuminates aging research," Journal on Active Aging, 15, 3, pp. 26-32, 2016.

[30] J. Shen, M. C. Anderson, K. H. Arehart, and P. E. Souza: "Using Cognitive Screening Tests in Audiology," American Journal of Audiology, 25, 4, pp. 319-331, 2016.

[31] National Institute of Aging: Strategic Directions for Research, 2020-2025, pp. 3-5, 2020.

[32] A. L. Gustman and T. L. Steinmeier: "Retirement, Saving, Benefit Claiming and Solvency Under a Partial System of Vountary Personal Accounts," SSRN Electronic Journal, 2005.

[33] A. W. Taylor, R. Pilkington, H. Feist, E. Dal Grande and G. Hugo: "A survey of retirement intentions of baby boomers: An overview of health, social, and economic determinants," BMC Public Health, 14, 1, 2014.

[34] E. Vogel, A. Ludwig, and A. Börsch-Supan: “Aging and pension reform: extending the retirement age and human capital formation," Journal of Pension Economics \& Finance, 16, 1, pp. 87-107, 2017.

[35] World Health Organization: "WHO global estimates on prevalence of hearing loss: Prevention on Deafness," 2018. 
[36] National Institutes of Health, National Institute on Deafness and Other Communication Disorders: "Quick Statistics About Hearing," 2016.

[37] A. M. Goman and F. R. Lin: "Prevalence of hearing loss by severity in the United States," American journal of public health, 106, 10, pp. 1820-1822, 2016.

[38] H. Karawani, K. A. Jenkins, and S. Anderson: "Neural and behavioral changes after the use of hearing aids," Clinical Neurophysiology, 129, 6, pp. 1254-1267, 2018.

[39] P. C. M. Wong, J. X. Jin, G. M. Gunasekera, R. Abel, E. R. Lee, and S. Dhar: "Aging and cortical mechanisms of speech perception in noise," Neuropsychologia, 47, 3, pp. 693-703, 2009.

[40] P. Dawes, R. Emsley, K. J. Cruickshanks, D. R. Moore, H. Fortnum, M. Edmondson-Jones, A. McCormack and K. J. Munro: "Hearing loss and congition: The role of hearing aids, social isolation and depression," PLoS ONE, 10, 3, pp. 1-9, 2015.

[41] S. Anderson, T. White-Schwoch, A. Parbery-Clark and N. Kraus: "A dynamic auditory-cognitive system supports speech-in-noise perception in older adults," Hearing Research, 300, pp. 18-32, 2013.

[42] N. K. Nagaraj: "Working memory and speech comprehension in older adults with hearing impairment," Journal of Speech, Language, and Hearing Research, 60, 10, pp. 2949-2964, 2017.

[43] W. T. Hsu, C. C. Hsu, M. H. Wen, H. C. Lin, H. t. Tsai, P. Su, C. Te, Sun, C. L. Lin, C. Y. Hsu, K. H. Chang and Y. C. Hsu: "Increased risk of depression in patients with acquired sensory hearing loss A 12year follow-up study," Medicine (Baltimore), 95, 44, 2016.

[44] A. Heinrich, H. Henshaw and M. A. Ferguson: "The relationship of speech intelligibility with hearing sensitivity, cognition, and perceived hearnig difficulties varies for different speech perception tests," Frontiers in Psychology, 6, June, pp. 1-14, 2015.

[45] F. N. Martin, C. A. Champlin and D. D. Perez: "The question of phonetic balance in word recognition testing," Journal of the American Academy of Audiology, 11, 9, pp. 489-493, 2000.

[46] A. W. Bronkhorst: "The cocktail party phenomenon: A review of research on speech intelligibility in multiple-talker conditions," Acta Acustica united with Acustica, 86, 1, pp. 117-128, 2000.

[47] N. M. Etter, E. R. Hapner, J. M. BarkmeierKraemer, J. L. Gartner-Schmidt, E. V. Dressler, and J. C. Stemple: "Aging Voice Index (AVI): Reliability and validity of a voice quality of life scale for older adults," Journal of Voice, 33, 5, pp. 807-e7, 2019.

[48] ASHA: "Type, Degree, and Configuration of Hearing Loss," ASHA Audiology Information Series, 2015.

[49] J. G. Clark: "Uses and abuses of hearing loss classification,” ASHA, 23, 7, pp. 493-500, 1981

[50] R. H. Wilson, K. E. Coley, J. L. Haenel and K. M. Browning: "Northwestern University Auditory Test No. 6: normative and comparative intelligibility functions," Journal of the American Audiology Society, 1, 5, pp. 221-228, 1976.

[51] "ISO 3382-2, 2008, Acoustics - Measurement of Room Acoustic Parameters - Part 2: Reverberation Time in Ordinary Rooms," International Organization for Standardization, Belgium, Brussels, 2008. 